CARVALHO, L.M.; CASALI, V.W.D.; SOUZA, M.A.; CECON, P.R. Disponibilidade de água no solo e crescimento de artemísia. Horticultura brasileira, Brasília, v. 21, n. 4, p. 726-730, outubro-dezembro, 2003.

\title{
Disponibilidade de água no solo e crescimento de artemísia
}

\author{
Luciana M. de Carvalho ${ }^{1}$; Vicente Wagner D. Casali $^{3}$; Márcio A. de Souza ${ }^{3}$; Paulo R. Cecon ${ }^{4}$ \\ ${ }^{2}$ Embrapa Tabuleiros Costeiros Aracaju-SE; ${ }^{3} \mathrm{UFV}, 36571-000$ Viçosa-MG;
}

\begin{abstract}
RESUMO
Plantas de artemísia (Tanacetum parthenium L. Schultz-Bip.), cultivadas em vasos com substrato mantido na capacidade de campo, a $90 \%$, a $70 \%$ e a $50 \%$ da capacidade de campo foram comparadas quanto à altura, acúmulo de massa fresca na parte aérea, teor relativo de clorofila e teor de prolina. O teor relativo de clorofila foi estimado por meio do clorofilômetro SPAD-502, enquanto o teor de prolina foi determinado por colorimetria. Verificou-se reduções de $16 \%$ na altura e de $22,5 \%$ no acúmulo de massa fresca nas plantas crescidas a $50 \%$ da capacidade de campo, em relação àquelas crescidas a $90 \%$ da capacidade de campo. O teor relativo de clorofila nas folhas, em quaisquer dos níveis hídricos, decresceu com o tempo, indicando tendência à senescência. Apesar da redução contínua nos níveis de clorofila, as plantas mantidas a $50 \%$ da capacidade de campo tiveram, durante todo o tempo acompanhado, teor relativo de clorofila cerca de $30 \%$ mais alto comparado às plantas mantidas a $90 \%$ da capacidade de campo. O teor de prolina também foi maior nessas plantas, indicando ocorrência de estresse por deficiência hídrica e ajuste osmótico. O maior teor relativo de clorofila e de prolina nas folhas expandidas das plantas sob deficiência hídrica pode ser utilizado como indicativo de estresse.
\end{abstract}

Palavras-chave: Tanacetum parthenium, planta medicinal, estresse hídrico, deficiência hídrica.

\begin{abstract}
Soil water availability and growth of feverfew.

Feverfew plants (Tanacetum parthenium L. Schultz-Bip) were cropped in pots containing substratum maintained at $90 \%, 70 \%$ and $50 \%$ of field capacity. The plants were evaluated for the height, accumulation of fresh mass in the aerial part, relative chlorophyll and proline content. The relative chlorophyll content was estimated using a portable chlorophyll meter (SPAD-502), while the proline content was estimated by colorimetry. Reductions of $16 \%$ in the height and of $22,5 \%$ in the accumulation of fresh mass in the aerial part of the plants grown at $50 \%$ of field capacity were verified, being compared with the average of the plants grown at $90 \%$ of field capacity. The relative chlorophyll content in the expanded leaves, in any of substratum water levels, decreased with the time, indicating tendency to senescence of the leaves. Plants maintained at $50 \%$ of field capacity presented about $30 \%$ more chlorophyll, compared to plants at $90 \%$ of field capacity, during the whole accompanied time. Also, the proline content was higher, indicating osmotic adjustment stress due to water deficiency. The largest chlorophyll and proline accumulation in the expanded leaves of the plants under water deficiency can be used as a stress indicative.
\end{abstract}

Keywords: Tanacetum parthenium, medicinal plant, water deficiency, water stress.

\section{(Recebido para publicação em 25 de novembro de 2002 e aceito em 10 de outubro de 2003)}

\begin{abstract}
$\mathrm{A}$ rtemísia [Tanacetum parthenium (L.) Schultz.-Bip., sinonímia Chrysanthemum parthenium L. Bern.] (Asteraceae) é uma planta medicinal nativa no Sudeste Europeu e Ásia Menor, utilizada na profilaxia da enxaqueca. Apesar da origem européia, encontra-se bem estabelecida na América do Norte e do Sul e no Nordeste da África (Hendriks et al., 1996; Brown et al., 1999). A literatura etnobotânica registra o uso de suas flores e folhas, por via oral e local, no tratamento caseiro de muitas enfermidades como dores de cabeça, mal estar gástrico, diarréia, cólicas, reumatismo, câimbra e vermes (Lorenzi \& Matos, 2002). É uma planta perene, cultivada anual e fortemente aromática. Seu caule é vertical e ereto, rígido, coberto por pêlos, com altura va-
\end{abstract}

riando de 25 a $120 \mathrm{~cm}$. O forte odor, característico da espécie, é decorrente do óleo essencial, encontrado especialmente em folhas e flores (Abad et al., 1995; Berry, 1984; Figueiredo, 1998).

Estudos recentes têm indicado que plantas de qualidade podem ser obtidas por meio de sistemas de reduzida irrigação (Morvant et al.,1998). A deficiência de umidade altera vários processos bioquímicos e fisiológicos, e induz respostas metabólicas e fisiológicas como o fechamento estomático, declínio na taxa de crescimento, acúmulo de solutos e substâncias antioxidantes, e expressão de genes específicos de estresse (Steponkus, 1990; Singh-Sangwan et al., 1994). Algumas mudanças podem causar injúria às plantas, no entanto outras ocorrem enquanto a planta ajusta- se fisiologicamente ao estado de menor disponibilidade de água.

Clorofila e carotenóides são os pigmentos biológicos e fotossintéticos mais abundantes no planeta. A perda de pigmentos durante estresse ambiental ou morte prematura é um indicador muito visível de eventos como doenças, aplicação de herbicidas, poluição ambiental, deficiência e toxicidade mineral, deficiência hídrica, extremos de temperatura, exposição a UV-B (Hendry \& Price, 1993). Tem sido demonstrada a existência de relação entre índice de intensidade da cor verde e teor de clorofila em várias espécies de plantas. O SPAD-502 é um equipamento, disponível atualmente no mercado, que determina o teor relativo de clorofila, medindo a transmissão de luz vermelha a $650 \eta \mathrm{m}$, re-

1 Trabalho executado com apoio do CNPq 
gião em que a clorofila absorve luz, e transmissão de luz infravermelha a 940 $\eta \mathrm{m}$, onde nenhuma absorção ocorre (Hoel \& Solhaug, 1998). É um instrumento utilizado na associação do teor relativo de clorofila das folhas com valores unidimensionais (índice de intensidade da cor verde) estabelecidos por esse medidor A relação entre teor de clorofila e leituras do SPAD-502 foram estabelecidas em várias espécies de plantas como arroz, milho, trigo, mamão, entre outras (Torres Netto et al., 2002). Esse equipamento vem sendo muito estudado e utilizado por permitir estimar o teor de clorofila de modo não destrutivo, rápido e preciso.

O lento desenvolvimento de deficiência hídrica pode induzir ajuste osmótico em algumas espécies, resultando na manutenção da turgescência celular a baixos potenciais hídricos durante condição de seca. $O$ ajuste osmótico é importante mecanismo de tolerância à seca, porque capacita a planta a continuar com a expansão celular, realizar ajustes estomáticos e fotossintéticos, melhorar o crescimento vegetal e ter, em alguns casos, produção rentável (Heuer, 1994; Kumar \& Singh, 1998).

Detalhes significativos das respostas fisiológicas e metabólicas das culturas agrícolas a ambientes secos são conhecidos, mas sobre o comportamento das plantas medicinais e aromáticas com limitada disponibilidade de umidade pouco se sabe (Singh-Sangwan et al., 1994; Letchamo \& Gosselin, 1996). Assim esse trabalho teve por finalidade determinar efeitos de quatro níveis de água no substrato sobre o crescimento da parte aérea de plantas de artemísia em quatro épocas de colheita.

\section{MATERIAL E MÉTODOS}

Plantas de artemísia foram transplantadas para vasos de cinco litros, preenchidos com substrato constituído por terra: areia: esterco bovino decomposto, na proporção de $3: 2: 1$, quando tinham, em média, $8,5 \mathrm{~cm}$ de altura e 15 a 20 folhas. O substrato dos vasos foi irrigado diariamente até o início do controle hídrico, por meio de regador de crivos finos, até o ponto em que, devido à drenagem, começou a sair a água em excesso dos vasos. Desse modo manteve-se os vasos umedecidos na sua capacidade por 17 dias. A terra utilizada no preparo do substrato foi retirada de um latossolo vermelho-amarelo. Amostras do substrato dos vasos foram analisadas na UFV, resultando em boa disponibilidade de bases trocáveis (valor de soma de bases, $\mathrm{SB}=6,02 \mathrm{cmol} / \mathrm{dm}^{3} \mathrm{e}$ de saturação de bases, $\mathrm{V}=78 \%$ ) e ótima disponibilidade de fósforo $(268 \mathrm{mg} /$ $\left.\mathrm{dm}^{3}\right)$.

O experimento foi conduzido a pleno sol na Universidade Federal de Viçosa (UFV), de maio a setembro de 1999, no delineamento de blocos ao acaso, quatro repetições, em parcelas subdivididas, tendo nas parcelas os níveis de água $(100 \%, 90 \%, 70 \%$ e $50 \%$ da capacidade de campo do substrato) e nas subparcelas as épocas de colheita (30; 60; 90 e 120 dias após início do controle hídrico). Os dados obtidos foram analisados utilizando-se a técnica de superfície de resposta. Os modelos foram escolhidos baseando-se na significância dos coeficientes de regressão, por meio do teste de $\mathrm{t}$, a $5 \%$ de probabilidade e no coeficiente de determinação.

A capacidade de campo foi determinada previamente (Carvalho, 2001), por meio da curva de retenção de umidade, a partir do substrato seco, peneirado e homogeneizado em laboratório, segundo técnicas de rotina do Laboratório de Física do Solo, da UFV.

$\mathrm{O}$ estabelecimento e controle dos níveis hídricos foi feito, nos vasos de todos os blocos, de cada nível hídrico, por meio do monitoramento diário da massa de uma amostra, constituída de quatro vasos por nível hídrico, incluindo seu substrato e a planta. Previamente determinou-se a massa referência, ou seja a massa que cada vaso precisava ter, em cada nível hídrico. Isso foi feito a partir dos dados da massa do vaso vazio, da massa do vaso com substrato seco e na capacidade de campo, e do grau de umidade do substrato na capacidade de campo (Carvalho, 2001). A cada dia, após a pesagem dos vasos, comparava-se essa massa com a massa referência, calculava-se a diferença, completando-se a massa do vaso com o volume de água correspondente. Uma amostra, em cada bloco, de quatro vasos mantidos na capacidade de campo durante todo o tempo do experimento, foi utilizada visando aferir as massas dos vasos, a cada quatro semanas, alterados devido ao incremento propiciado pelo crescimento das plantas.

As épocas de amostragem ou de colheita foram determinadas a partir dos resultados de Hendriks et al. (1997) e de Figueiredo (1998), com plantas de artemísia cultivadas em casa de vegetação. As colheitas foram feitas manualmente, cortando-se o caule rente ao solo com tesoura de poda, sempre entre 7:00 e 9:30 horas. As plantas, logo que colhidas, foram colocadas separadamente em sacos de papel tipo Kraft, previamente identificados. Amostras foliares foram então retiradas de cada planta da unidade experimental para posterior extração e determinação do teor de prolina. Em seguida, as plantas foram pesadas e levadas à sala de secagem, onde desidrataram à temperatura ambiente, mantendo-se a umidade em torno de $50 \%$, por meio de desumidificador.

Os efeitos dos níveis hídricos do substrato sobre o crescimento das plantas foram estimados por meio de determinações periódicas da altura e da massa fresca da parte aérea das plantas. Com o objetivo de verificar se as plantas sofreram estresse por deficiência hídrica no substrato dos vasos, determinou-se o teor total de prolina nas folhas expandidas do terço superior das plantas. A extração de prolina foi feita, em cada época de colheita, a partir de $300 \mathrm{mg}$ de amostra de folhas frescas homogeneizadas em $10 \mathrm{ml}$ de ácido sulfosalicílico a $3 \%$ por cerca de 2 minutos. A estimativa do teor de prolina foi feita segundo método colorimétrico de Bates et al. (1973).

Com a mesma finalidade, o teor relativo de clorofila foi estimado, de modo não destrutivo, nas mesmas folhas, utilizando-se o clorofilômetro Minolta SPAD-502. Os valores SPAD ("Soil Plant Analysis Development”) são calculados, pelo equipamento, com base na quantidade de luz transmitida pela folha, em dois comprimentos de onda, 650 $\mathrm{hm}$ e $940 \eta \mathrm{m}$, com diferentes absorvâncias da clorofila (Hoel \& Solhaug, 1998). Considerando-se que o 
Tabela 1. Equações dos modelos de superfície de resposta e respectivo coeficiente de determinação das variáveis altura, e massa fresca de plantas de Tanacetum parthenium crescidas em vasos mantidos a $100 \%, 90 \%, 70 \%$ ou $50 \%$ da capacidade de campo do substrato (A) com 0, 30, 60, 90 e 120 dias após início do controle hídrico do solo (E). Aracaju, Embrapa Tabuleiros Costeiros, 2001.

\begin{tabular}{llc}
\hline \multicolumn{1}{c}{ Variável } & \multicolumn{1}{c}{ Equação } & $\mathbf{R}^{\mathbf{2}}$ \\
\hline Altura & $\mathrm{Y}=-31,0502+1,17312^{* *} \mathrm{~A}-0,00799654^{* *} \mathrm{~A}^{2}+0,143925^{* *} \mathrm{E}+$ & 0,97 \\
Massa fresca & $0,00132887^{* *} \mathrm{E}^{2}+0,00164014^{* *} \mathrm{~A} E$ & 0,88 \\
\hline
\end{tabular}

$*, * * \mathrm{e}^{\text {ns }}$ indicam significância a $5 \%, 1 \%$ ou não significativo a $5 \%$ de probabilidade pelo teste $\mathrm{F}$.

SPAD-502 realiza leituras de modo não destrutivo e preciso, e que os valores obtidos são proporcionais ao teor relativo de clorofila presente na folha (Hoel \& Solhaug, 1998; Egert \& Tevini, 2002; Torres Netto et al., 2002; Chang \& Robinson, 2003), optou-se por estimar os efeitos dos níveis hídricos, em cada época de colheita, sobre o teor relativo de clorofila com base na leitura desse equipamento. A medição foi feita unicamente com o clorofilômetro, com o intuito de apenas comparar os níveis de clorofila entre os tratamentos, e não de estabelecer o teor de clorofila nas plantas de artemísia. Desse modo, não foi feita calibração e transformação das leituras do SPAD com análises espectrométricas.

\section{RESULTADOS E DISCUSSÃO}

As variáveis altura e massa fresca da parte aérea das plantas de artemísia tiveram comportamento quadrático (Tabela 1). Fixando-se o nível de água no substrato dos vasos, verificou-se maior altura $(0,61 \mathrm{~m}) 116$ dias após início do controle hídrico do substrato dos vasos, nas plantas crescidas a $90 \%$ da capacidade de campo, e menor altura nas plantas mantidas a $50 \%(0,51 \mathrm{~m})$ da capacidade de campo. O acúmulo máximo de massa fresca (137,4 gramas), obtido fixando-se o nível de água no substrato, ocorreu nas plantas a $90 \%$ da capacidade de campo, 94 dias após o início do controle hídrico. Nesse mesmo dia, as plantas mantidas a $50 \%$ da capacidade de campo tinham cerca de $105,9 \mathrm{~g}$ de massa fresca.

Considerando-se as plantas crescidas em substrato a $90 \%$ da capacidade de campo como referência, verificou-se que a redução no nível hídrico do substrato de $90 \%$ para $50 \%$ da capaci- dade de campo causou decréscimo de $16 \%$ na altura e de $23 \%$ no acúmulo de massa fresca na parte aérea das plantas. Esses dados são similares aos descritos por Schuch et al. (1998), em plantas de Chrysanthemum mantidas em sistema de reduzido volume de irrigação (30\% a menos do que o controle) por dez semanas consecutivas. Segundo Kudrev (1994), a deficiência hídrica interrompe o processo de crescimento, não apenas diminuindo o acúmulo de massa fresca e seca, mas também alterando o processo de crescimento, e acelerando os processos catabólicos.

A variável valor do SPAD (Figura 1a) teve comportamento quadrático. Os valores do SPAD tenderam, após 50-60 dias de controle hídrico, a decrescer com o tempo, em qualquer dos níveis hídricos, indicando início de senescência foliar. Fixando-se o nível de água no substrato obteve-se maior leitura do SPAD-502 nas plantas a 50\% da capacidade de campo, aos 50 dias após início do controle hídrico do substrato: 47,1 SPAD, enquanto as plantas a $100 \mathrm{e}$ $90 \%$ da capacidade de campo do substrato tinham 37,2 e 36,1 SPAD, respectivamente. Considerando as plantas crescidas a $90 \%$ da capacidade de campo como referência na comparação do efeito dos níveis hídricos sobre essa variável, verificou-se que o teor relativo de clorofila nas plantas a 50\% da capacidade de campo foi $30 \%$ maior nesse período.

Similarmente, Nautiyal et al. (1996) verificaram em plantas de Pongamia pinnata submetidas a intervalos de irrigação de até 15 dias aumento no teor de clorofila a, b e total. No entanto, os mesmos autores verificaram rápida redução nesses teores quando o intervalo de irrigação foi igual ou maior a 30 dias. Segundo esses autores, isso mostra que a referida espécie é capaz de sobreviver e manter-se fotossinteticamente ativa em condições moderadas de défice hídrico, mas condições mais severas têm efeito adverso sobre o teor de clorofila. Segundo Rey et al. (1999), sob condições moderadas de estresse hídrico há redução na assimilação fotossintética de $\mathrm{CO}_{2}$ devido ao aumento da resistência à difusão de $\mathrm{CO}_{2}$, em conseqüência de fechamento estomático. A deficiência hídrica severa, por outro lado, favorece a formação de espécies reativas de oxigênio, que danificam as plantas oxidando pigmentos fotossintéticos, lipídeos de membrana, proteínas e ácidos nucléicos. Decréscimos nos teores de clorofila ou proteína podem, portanto, ser sintoma característico de estresse oxidativo, e tem sido verificado em plantas sob estresse hídrico (Smirnoff, 1995).

Ejert \& Tevini (2002) não verificaram alteração significativa nos teores de clorofila, proteínas e compostos antioxidantes quando expuseram a planta condimentar Allium schoenoprosum a seca, o que segundo eles indica ausência de estresse oxidativo. Apesar da destruição de pigmentos fotossintéticos devido a dano oxidativo ser sintoma comum em plantas expostas a estresse hídrico severo, as plantas podem, segundo Ejert \& Tevini (2002) proteger-se sintetizando antioxidantes (carotenóides, ascorbato, $\alpha$-tocoferol, glutationa e flavonóides) e aumentando o teor de enzimas antioxidantes (peroxidases, superóxido dismutase e catalases).

O teor de prolina livre, por sua vez, nas folhas expandidas de T. parthenium mantidas a $100 ; 90 ; 70$ ou $50 \%$ da capacidade de campo do substrato (Figura 1b), variou em torno de 9 a $14 \mathrm{mg} / \mathrm{g}$ de massa fresca, enquanto que nas plantas mantidas em solos a $50 \%$ da capacidade de campo variou em torno de 27 a 32 


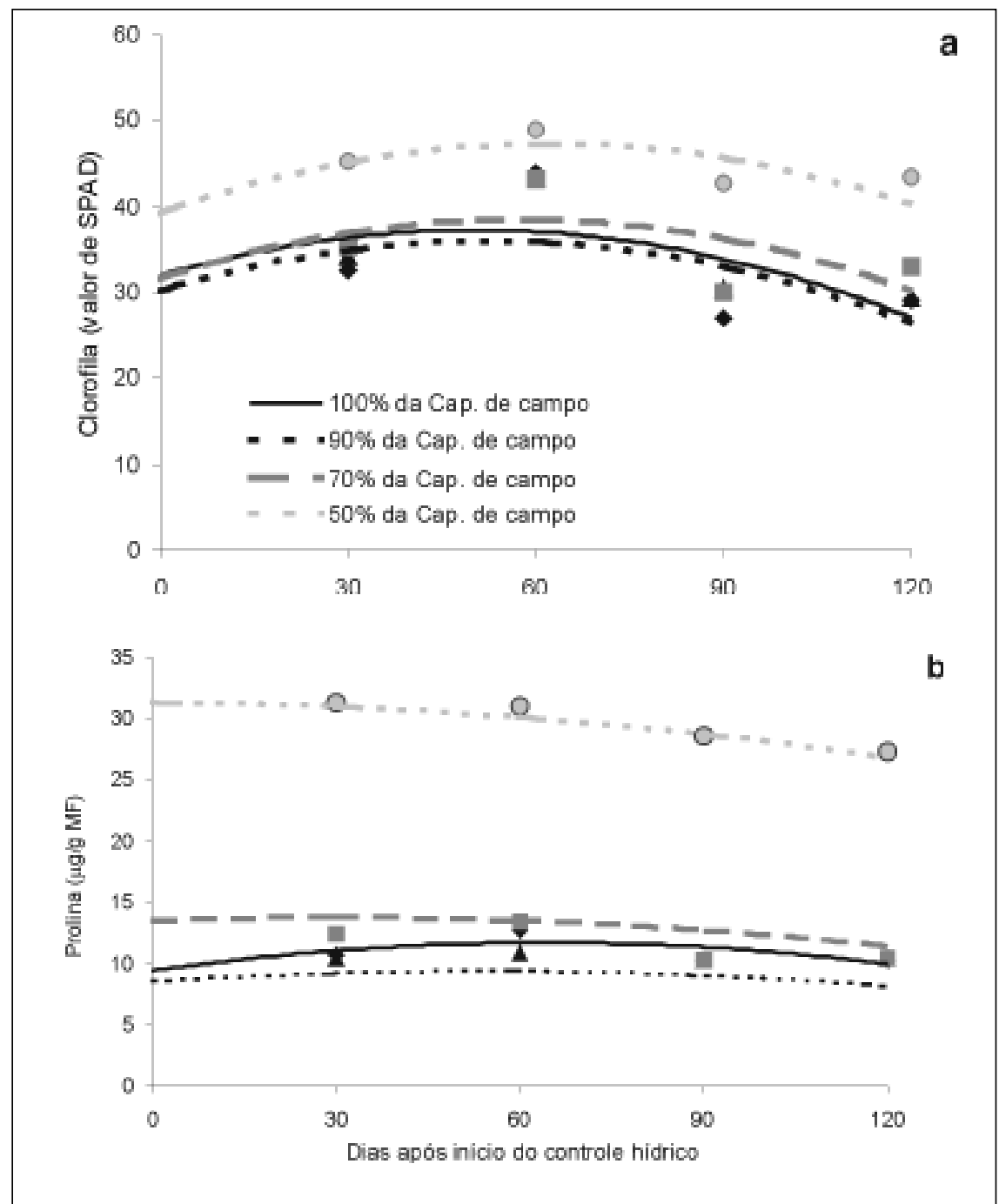

Figura 1. Estimativa do (a) valor do SPAD e do (b) teor de prolina em folhas de Tanacetum parthenium, nas condições de $100 \%, 90 \%, 70 \%$ e $50 \%$ da capacidade de campo do substrato, em função da época de colheita, em dias após início do controle hídrico do substrato. Viçosa(MG), UFU, 1999.

$\mathrm{mg} / \mathrm{g}$ de massa fresca. A redução na disponibilidade de água no solo de 90 a $50 \%$ da capacidade de campo do solo, portanto, causou grande aumento no teor de prolina livre dessas plantas, o que segundo Bates et al. (1973), é sintoma característico de estresse. A tendência ao maior acúmulo de prolina livre e não combinada em plantas crescidas em condição de deficiência hídrica é, freqüentemente, verificada em várias plantas (Kumar \& Singh, 1998). Além disso, o maior acúmulo de prolina sugere a ocorrência de ajuste osmótico nessas plantas. $\mathrm{O}$ acúmulo $30 \%$ maior no teor relativo de clorofila nas plantas crescidas em substrato a $50 \%$ da capacidade de campo, pode ser indicativo do estresse por defi-
BATES, L.S.; WALDREN, R.P.; TEARE, J.D. Rapid determination of free proline for waterstress studies. Plant and Soil, v. 39, p. 205-207, 1973.

BERRY, I. Feverfew faces the future. The pharmaceutical Journal, v. 232, p. 611-614, 1984. BROWN, A.M.G.; EDWARDS, C.M.; HARTMANN, T.T.V.; MARSHALL, J.A.; SMITH, R.M.; DAVEY, M.R.; POWER, J.B.; LOWE, K.C. Sexual hybrids of Tanacetum: biochemical, cytological and pharmacological characterization. Journal of Experimental Botany, v. 50, p. 435-444, 1999.

CARVALHO, L.M. Disponibilidade de água, irradiancia e homeopatia no crescimento e teor de partenolídeo em Artemísia. 2001. 139 p. (Tese doutorado), UFV, Viçosa.

CHANG, S.X.; ROBISON, D.J. Nondestructive and rapid estimation of hardwood foliar nitrogen status using the SPAD-502 chlorophyll meter. Forest Ecology and Management, v. 6215, p. 1-8, 2003.

EGERT, M.; TEVINI, M. Influence of drought on some physiological parameters symptomatic for oxidative stress in leaves of chives (Allium schoenoprasum). Environmental and Experimental Botany, v. 48, p. 43-49, 2002.

FIGUEIREDO, L.S. Germinação e Crescimento de Tanacetum parthenium (L.) Schultz Bip. 1998. 62 p. (Tese mestrado), UFV, Viçosa.

HENDRIKS, H.; BOS, WOERDENBAG, H.J. The essential oil of Tanacetum parthenium (L.) Schultz-Bip. Flavour and Fragrance Journal, v. 11, p. 367-371, 1996.

HENDRIKS, H.; ANDERSON-WILDEBOER, Y.; ENGELS, G.; BOS, R.; WOERDENBAG, H.J. The content of parthenolide and its yield per plant during the growth of Tanacetum parthenium. Planta Medica, v. 63, p. 356-359, 1997.

HENDRY, G.A.F.; PRICE, A.H. Stress indicators: chlorophylls and carotenoids. In: Hendry, G.A.F.; Grime, J.P. (eds), Methods in Comparative Plant Ecology, p. 148-152. London, Chapman \& Hall, 1993.

HEUER, B. Osmoregulatory role of proline in water and salt stress plants. In: M. Pessarakli (ed.). Handbook of plant and crop stress. New York, Marcel Dekker. 1994.

HOEL, B.O.; SOLHAUG, K.A. Effect of irradiance on chlorophyll estimation with the Minolta SPAD-502 leaf chlorophyll meter. Annals of Botany, v. 82, p. 389-392,1998.

KUDREV, T.G. Água: vida das plantas. Trad. José Glicério de Rezende. São Paulo: Ícone, 178 p., 1994. KUMAR, A.; SINGH, D.P. Use of physiological indices as a screening technique for drought to tolerance in oilseed Brassica species. Annals of Botany, v. 81, p. 413-420, 1998.

LETCHAMO, W.; GOSSELIN, A. Transpiration, essential oil glands, epicuticular wax and morphology of Thymus vulgaris are influenced by light intensity and water supply. Journal of Horticultural Science, v. 71, p. 123-134, 1996.

LORENZI, H.; MATOS, F.J.A. Plantas medicinais no Brasil: nativas e exóticas. Nova Odessa, SP : Instituto Plantarum, 512 p., 2002.

MORVANT, J.K.; DOLE, J.M.; COLE, J.C. Irrigation frequency and system affect Poinsettia growth, water use, and runoff. HortScience, v. 33, p. $42-46,1998$. 
NAUTIYAL, S.; NEGI, D.S.; KUMAR, S. Effect of water stress and antitranspirants on the chlorophyll contents of the leaves of Pongamia pinnata (L.) Pierre. The Indian Forester, v. 122, p. 1018-1022, 1996.

REY, P.; PRUVOT, G.; GILLET, B.; PELTIER, G. Molecular chracterization of two chloroplastic proteins induced by water deficit in Solanum tuberosum L. plants: involvment in the response to oxidative stress. In: Smallwood, M.F.; Calvert, C.M.; Bowles, D.J. (eds.). Plant responses to environmental stress, p. 145-152. Oxford, BIOS Scientific Publishers, 1999.
SCHUCH, U.K.; REDAK, R.A.; BETHKE, J.A. Cultivar, fertilizer, and irrigation affect vegetative growth and susceptibility of Chrysanthemum to western flower thrips. Journal of American Society of Horticultural Science, v. 123, p. 727-733, 1998.

SINGH-SANGWAN, N.; FAROOQI, A H.A; SINGH-SANGWAN, R. Effect of drought stress on growth and essential oil metabolism in lemongrasses. New Phytologist, v. 128, p. 173179, 1994.

SMIRNOFF, N. Metabolic flexibility in relation to the environment. In: Environment and plant metabolism: flexibility and acclimation. Oxford: Bios Scientific publishers, 1995. p. 1-13.
STEPONKUS, P.L. Cold acclimation and freezing injury from a perspective of the plasma membrane. In: KATTERMAN, F. (Ed.). Environmental injury to plants. London: Academic Press, 1990. cap. 1, p. 1-15.

TORRES NETTO, A.; CAMPOSTRINI, E.; OLIVEIRA, J.G.; YAMANISH, O.K. Portable chlorophyll meter for the quantification of photosynthetic pigments, nitrogen and the possible use for assessment of the photochemical process in Carica papaya L. Brazilian Journal of Plant Physiology, v. 14, p. 203-210, 2002. 